\title{
Curing Studies on Modified Epoxy and Unsaturated Polyester Resins
}

\author{
ARVIND SHUKLA* and R. M. V. G. K. RAO, Materials Science Division, \\ National Aeronautical Laboratory, Bangalore-560 017, India
}

\section{Synopsis}

Experimental studies were carried out on the curing behavior of unsaturated polyesters and epoxy resins. The latter were modified with three different fillers $\left(\mathrm{CaCO}_{3}, \mathrm{CaSiO}_{3}\right.$, and glass powder $)$ and their curing behaviors studied. Polyesters exhibited faster cure rates than the epoxy resins. The gel time of the epoxy resins decreased with the addition of fillers. Data indicated that the peak exotherm of these thermosetting resins increased when filled with glass powder. The hardness of the curing mass increased with curing time. The use of gel-hardness number as a quality control parameter has been suggested.

\section{INTRODUCTION}

Additives are used in polymer matrices ${ }^{1}$ for different purposes, like plasticization, polymer toughening, reinforcement, wear resistance, flame retardancy, environmental stability, and the.like sidedequate wetting of the filler by the polymer as well as their mutual compatibility is essential ${ }^{2}$ for effective development of such modified formulations.

The role of oxidizer type of fillers in propellant formulations is no less significant. Flame-retardant polymers ${ }^{3}$ have emerged as a specific class of leading composite materials.

When used in thermosetting resins, the filler has a direct influence on the curing parameters like the gel time and'gel temperature. The complexity of such an effect largely depends on how much the filler absorbs or adsorbs the resin, the surface area of such fillers ${ }^{4}$ as well as their physicochemical interactions with the polymer meterices. Rao and Pourassamy, ${ }^{5}$ while studying the curing behavior of filled polyesters reported that, in case of nonabsorbing or adsorbing type of fillers, the surface area played an important role.

In the present studies, the curing behavior of the unfilled unsaturated polyester resins (AMSILITE 2100 and FORMAC 1009) was compared with that of epoxy resins (LY 556, CY 205, AW 106, and AW 103). The effects of filler addition and its loading on the curing characteristics of an epoxy resin system were reported. Hardness number of the curing mass at gel point was suggested to be a usęful parameter in studying the quality of different batches of resins.

\section{EXPERIMENTAL}

The curing studies were carried out at room temperature $\left(28 \pm 1^{\circ} \mathrm{C}\right)$. In each experiment, about $50 \mathrm{~g}$ of resin were cured with appropriate curing agent, in a

- Department of Chemical Engineering, Birla Institute of Technology and Science, Pilani, India. 
TABLE I

Details of Materials Used to Study the Curing of Unfilled Resins

\begin{tabular}{ccccccc}
\hline $\begin{array}{c}\text { Sample } \\
\text { no. }\end{array}$ & \multicolumn{2}{c}{ Classification } & $\begin{array}{c}\text { Resin } \\
\text { wt }(\mathrm{g})\end{array}$ & $\begin{array}{c}\text { Hardener } \\
\text { wt }(\mathrm{g})\end{array}$ & $\begin{array}{c}\text { Catalyst } \\
\text { wt }(\mathrm{g})\end{array}$ & $\begin{array}{c}\text { Accelerator } \\
\text { wt }(\mathrm{g})\end{array}$ \\
\cline { 2 - 7 } & Polyester & Epoxy & & & \\
1 & AMSILITE 2100 & & 46.5 & - & 2.0 & 2.0 \\
2 & FORMAC 1009 & & 46.5 & - & 2.0 & 2.0 \\
3 & - & LY 556 & 44.0 & 6.0 & - & - \\
4 & - & CY 205 & 44.0 & 6.0 & - & - \\
5 & - & AW 106 & 50.0 & 7.5 & - & - \\
6 & - & AW 103 & 44.0 & 6.0 & - & - \\
\hline
\end{tabular}

100-cc glass beaker, the reaction mass being stirred continuously till the gelling occurred. Table I shows various resins and their curing agents used in these studies. Effects of fillers and filler content on the resin curing were studied, by loading the epoxy resin (AW 103), respectively, with $5 \%$ by weight each of glass powder, $\mathrm{CaCO}_{3}, \mathrm{CaSiO}_{3}$, and $5-25 \%$ by weight of the glass powder.

The gel time of the curing mass was noted at the time when mass became just rubbery and the corresponding temperature, as measured by a precision thermometer, was defined as the gel temperature. The peak exothermic temperature was recorded as the maximum temperature reached by the reaction mass. These measurements were repeated for all the resins, in their filled and unfilled forms. (i)

The hardness of the curing resin system was measured as a function of time from the instant the resin reached the gel point. $\mathrm{A}$ small quantity of the curing mass was quickly transferred into tn aluminum mould, prior to the gel state. The shore-D hardness number of this transferred mass was then measured as a function of time, simultaneously with the time-temperature history of the mass remaining in the glass beaker. These measurements called for extreme care.

The results are presented in Figures 1-4 and Table II.

\section{RESULTS AND DISCUSSION}

The curing curves for different resins (polyesters and epoxies) in their unfilled form, are given in Figure 1. It can be seen that the epoxy resins in general cure slower than the polyesters.

Table II shows the curing characteristics of these unfilled resins. It may be noted that the gel time as well as the gel temperature of polyester resins is lower

TABLE II

Curing Characteristics of Different Resins (Unfilled)

\begin{tabular}{|c|c|c|c|c|c|c|c|}
\hline \multirow{2}{*}{$\begin{array}{c}\text { Sample } \\
\text { no. }\end{array}$} & \multicolumn{2}{|c|}{ Classification } & \multirow{2}{*}{$\begin{array}{l}\text { Gel time } \\
(\min )\end{array}$} & \multirow{2}{*}{$\begin{array}{l}\text { Gel temp } \\
\left({ }^{\circ} \mathrm{C}\right)\end{array}$} & \multirow{2}{*}{$\begin{array}{l}\text { Peak exo- } \\
\text { therm }\left({ }^{\circ} \mathrm{C}\right)\end{array}$} & \multirow{2}{*}{$\begin{array}{l}\text { Hardness no. } \\
\text { at gel time }\end{array}$} & \multirow{2}{*}{$\begin{array}{c}\text { (Shore D) } \\
(\max )\end{array}$} \\
\hline & Polyester & Epoxy & & & & & \\
\hline 1 & - & LY 556 & 20.50 & 60 & 102 & 19.5 & 71.5 \\
\hline 2 & - & CY 205 & 27.00 & 63 & 110 & 12.5 & 78.0 \\
\hline 3 & - & AW 103 & 35.5 & 70 & 95 & - & 61.0 \\
\hline 4 & - & AW 106 & 16.0 & 70 & 108 & 12.0 & 63.0 \\
\hline 5 & AMSILITE 2100 & - & 19.25 & 55 & 105 & 19.0 & 64.0 \\
\hline 6 & FORMAC 1009 & - & 5.00 & 45 & 122 & 9.0 & 72.5 \\
\hline
\end{tabular}




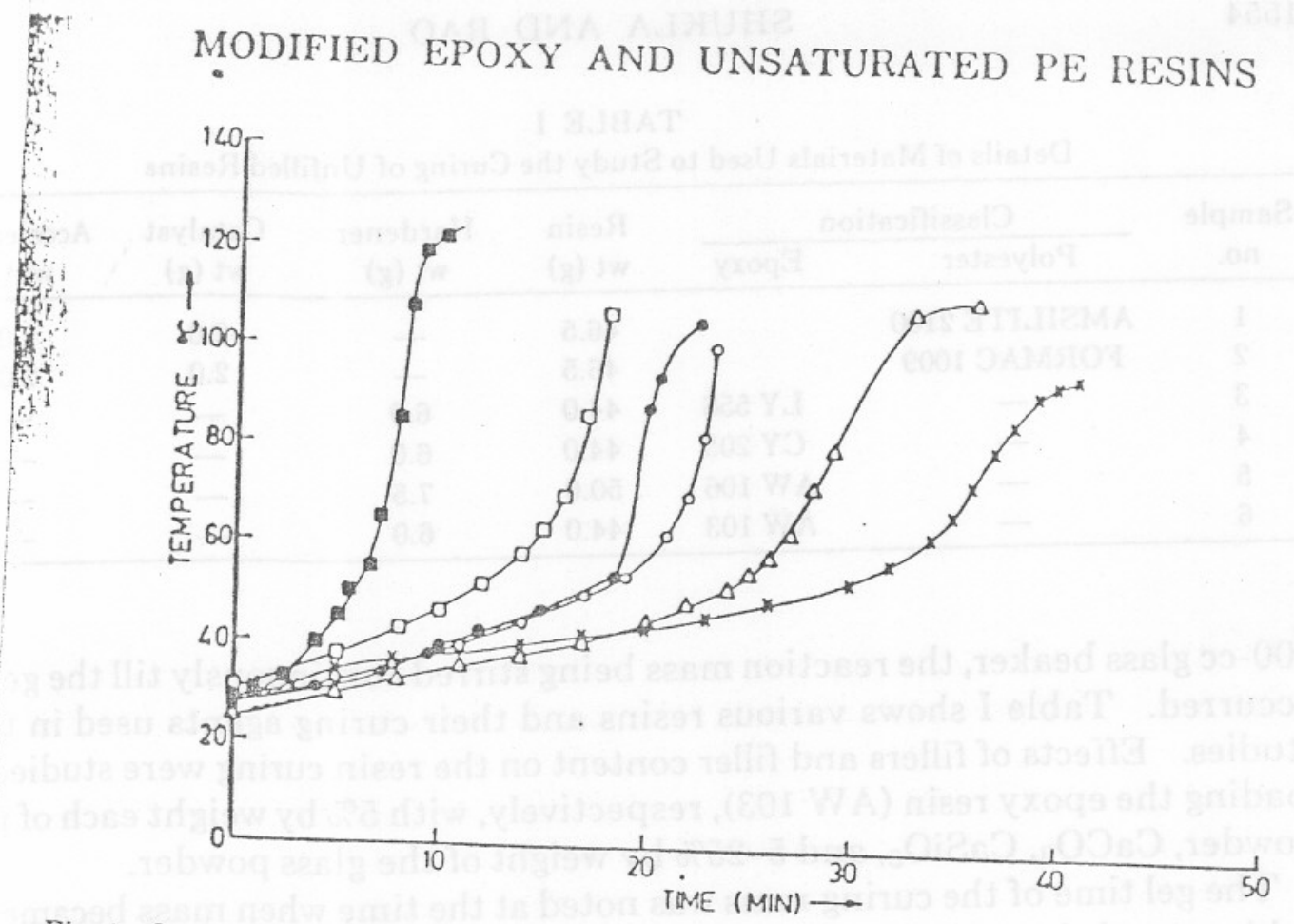
Fig. 1. Curing curves for different resins (without filler): (四) FORMAC 1009; (ㅁ) AW 106; (0)
AMSILITE 2100; (O) LY 556; ( $\triangle$ ) CY 205; (x) AW 103.

than those of the epoxies. Too low a gel time for one of the polyesters (Sample No. 6, Table II) may have been caused due to its low inhibitor content.

The time-hardness curves for the above resins (unfilled) are presented in Figure 2, which indicates that the time-hardness history of these thermosets essentially follows the same trend as exhibited by their time-temperature history
(Fig. 1).

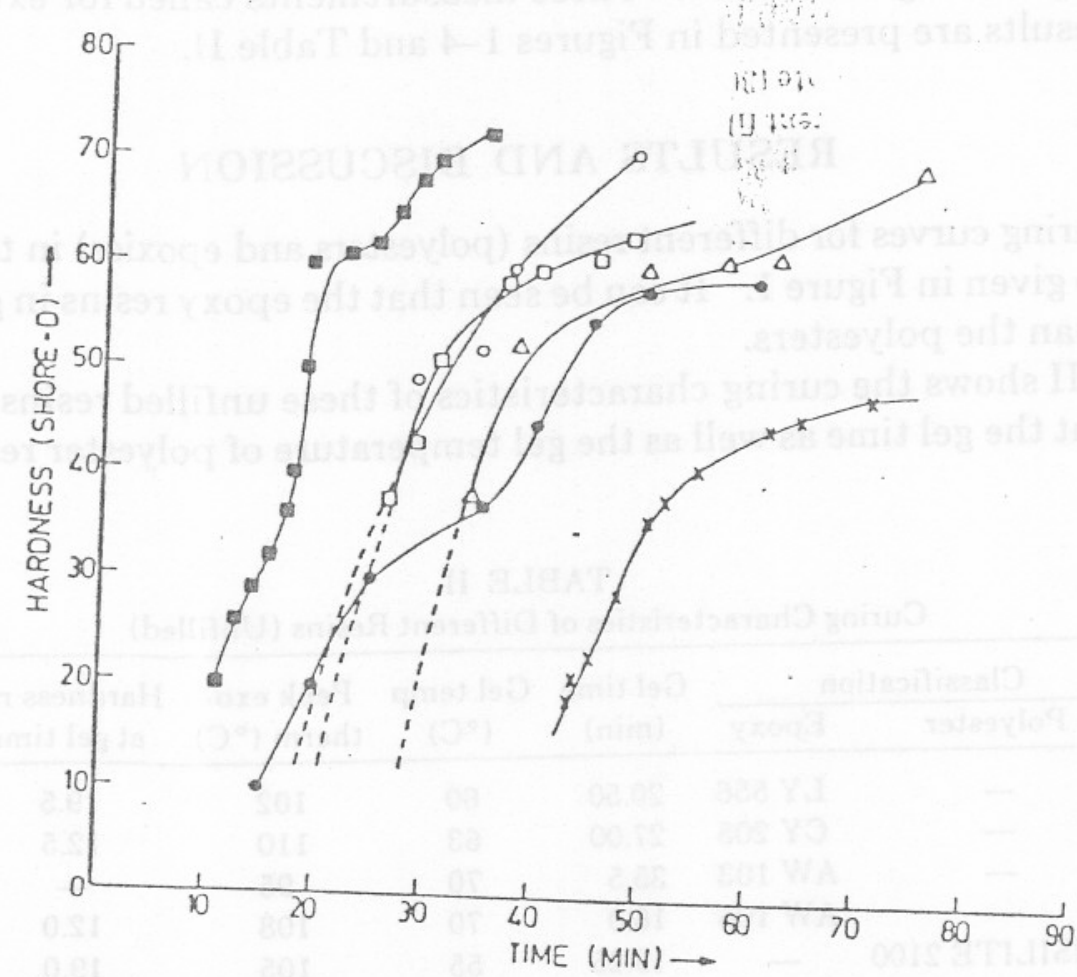

Fig. 2. Time hardness curves for different resins (without filler): (घ) FORMAC 1009; (ㅁ) AW 106; (๑) AMSILITE 2100; (O) LY 556; ( $\Delta$ ) CY 205; (X) AW 103 


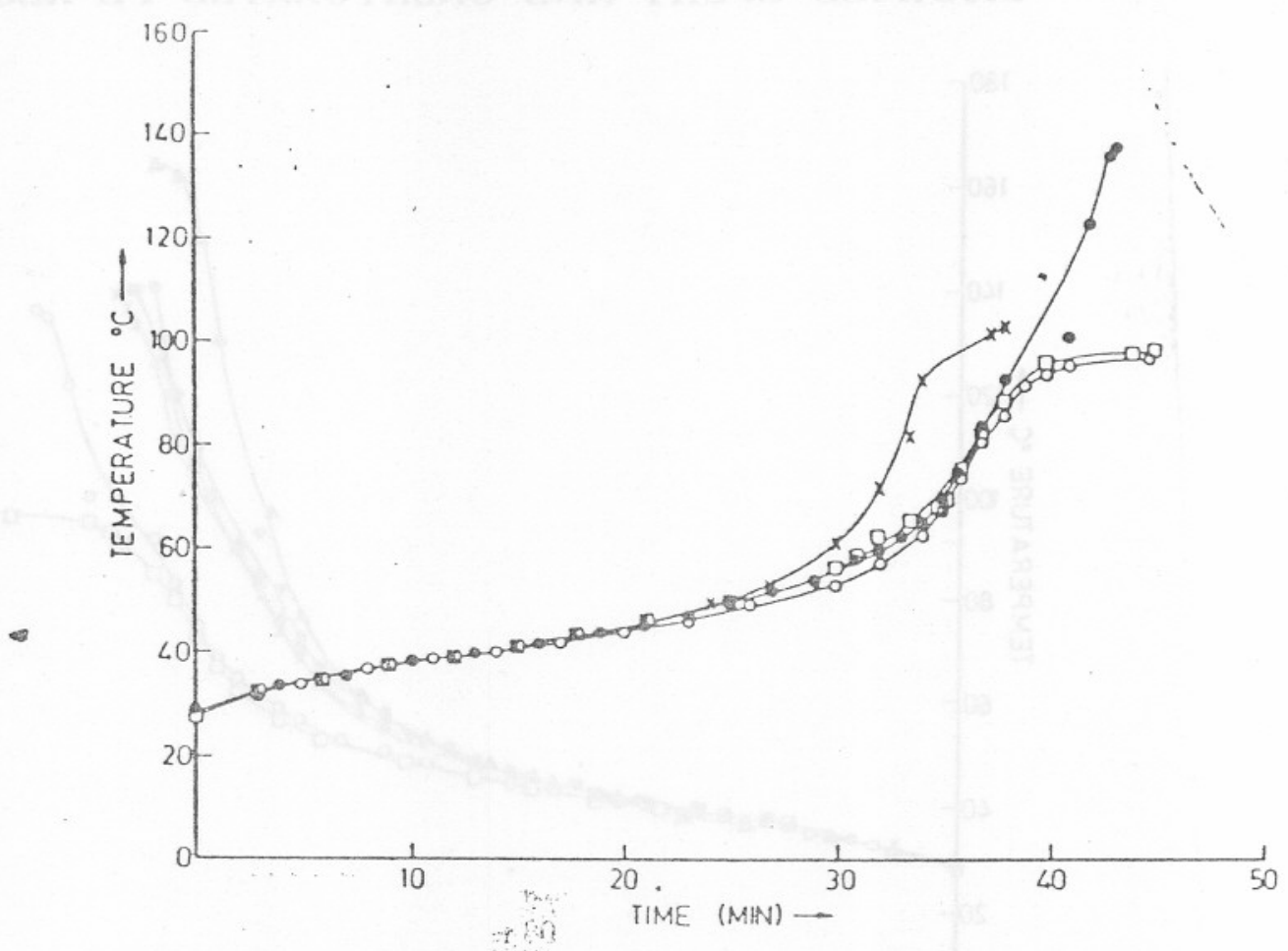

Fig. 3. Curing curves with different fillers: (AW 103 resin-HY 951 hardener with $5 \%$ filler): (O) without filler; ( $\square$ ) calcium carbonate ( $300 \mathrm{MESH})$; ( $)$ glass filler 80 mesh, $186 \mu \mathrm{m}$; (X) calcium sil. icate.

$$
\text { का }
$$

During the experiments, it was noted that, in general for epoxy resins, it would be difficult to measure the hardness number near the gel point, as they exhibited a too soft a state, with the temperature rising sharply. It was further noted that epoxides transformed into a solid mass without exhibiting a distinct rubbery state at gel point, as compared to the polyesters. For the latter, however, the reaction mass first changed into a rubbery state, which later started gaining hardness gradually. It was therefore easier in the latter case to obtain the hardness number as a function of curing time.

In view of the above problem, a two-stage method was adapted, to obtain the gel-hardness number. First the gel time was noted from experimental observations or from Figure 1, and then the hardness corresponding to this time was noted from Figure 2. The results are summed up as shown in Table II. 'This procedure was resorted to as it was found impracticable to obtain hardness values precisely at the gel point when curing was in progress. It was, however, verified that the hardness values so obtained were in close agreement with those that corresponded to the points where the time-hardness curves took a steep slope, as seen from Figure 2.

\section{Effects of Fillers}

One of the epoxy resins (AW 103) was chosen to study the effects of fillers, as this resin was found to offer the advantages of the highest gel time and lowest viscosity of all the resins studied.

Figure 3 shows the curing curves of this epoxy resin system with three different fillers. It can be clearly noted that addition of fillers reduces the gel time in 


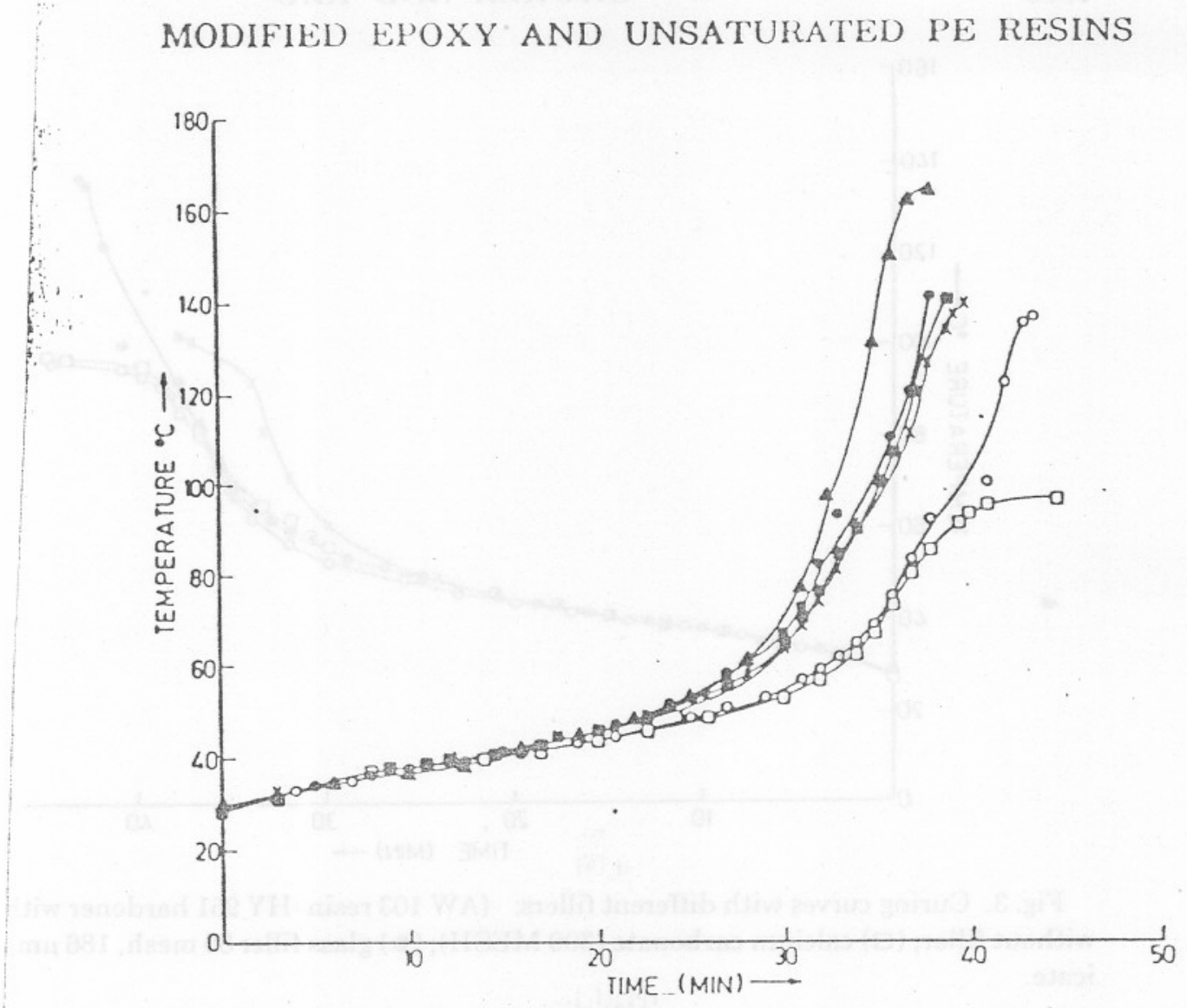

Fig. 4. Curing curves with different filler loadings (AW 103): (口) without filler; glass filler 80

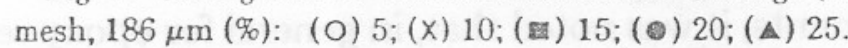

general and increases the peak exotherm to some extent. This result is similar to that reported by Rao and Pourassamy, ${ }^{5}$ for a loaded unsaturated polyester resin, indicating that the nonabsorbing type of fillers pays to lower the gel time, since their incorporation in the thermosetting resins enhances the effective surface area available for the curing reaction in progress.

It is interesting to note from Figure 3 that the glass-powder-filled epoxy resin system exhibits the highest peak exotherm, which can be attributed to the low thermal dissipation capacity of this filler. Figure 4 shows the curing behavior of the epoxy resin loaded with different proportions of the glass powder. It shows that the gel time decreases as the percent filler loading is increased, a result that can once again be attributed to the increased surface area made available for the curing mass with the progressive addition of the filler. It may also be seen that the peak exotherm increases with increased glass powder content, for obvious reasons.

\section{CONCLUSIVE COMMENTS}

The gel time and gel temperature of the unsaturated polyester resins are in general lower than those of the epoxy resins indicating faster cure rates for the former. The hardness of the curing resins increases with time and the former can be used as a useful cure parameter along with gel time and gel temperature for effective material characterization and batch-to-batch quality control.

Nonabsorbing type fillers reduce the gel time of the thermosetting resins, and 
those with low thermal conductivity increase the peak exotherm temperature in addition.

The authors are very thankful to Dr. A. K. Singh, Head, Materials Sciences Division, and Dr. S. R. Valluri, Director of this laboratory, for providing the facilities to conduct these studies and to Professor K. E. Raman for his keen involvement in this program. They acknowledge the timely as. sistance received from A. S. Selvanesan, M. Kodandaram, and C. Shankaran in specimen preparation and thank Mr. S. Gururaja and Mrs. N. Pushpalatha for typing these manuscripts.

\section{References}

1. L. Mascia, The Role of Additives in Plastics, Edward Arnold, London, 1974.

2. W. C. Wake, Fillers for Plastics, ILIFFE Publication, London, 1971.

3. Flame Retardant Polymeric Materials, Menachem, S. M. Atlas, and Eli M. Pearce, Eds.. Plenum, New York, 1978.

4. Handbook of Fillers for Reinforcements for Plastics, Harry S. Katz and John V. Milewski. Eds., Van Nostrand, New York, 1978.

5. R. M. V. G. K. Rao and A. Pourassamy, Polymer, 17, 611-612 (1976).

Received July 11, 1983

Accepted October 11, 1983 